\title{
Capas de livros ilustradas: projeções e visualidades
}

\author{
Maria Luísa Acioli Falcão de Alencar ${ }^{1}$ \\ Lucrécia D’Alessio Ferrara²
}

\begin{abstract}
Resumo
Colocando a ilustração como uma manifestação artística visual e, em alguns casos, tátil, estuda-se o contexto da estrutura de capa de livro e sua visualidade para exercer apelos ao desejo e curiosidade de leitores, levando-os ao manuseio e à compra do objeto livro. Através da análise da materialidade gráfica e estrutural da produção da capa e suas ilustrações, busca-se entender o papel que exercem sobre o público, enquanto leitores projetados. A partir de seleção de exemplares de capas pertencentes ao mercado editorial independente, procuramos entender a visualidade da capa como elemento persuasivo que fundamenta a ação daquele mercado.
\end{abstract}

\section{Palavras-chave}

Ilustração. Capa de livro. Visualidade.

\begin{abstract}
Setting Illustration as an artistic and visual manifestation, in some cases, also tactile, is studied the context of book covers and its visuality in performing appeals to readers' desire and curiosity, leading them to handling and buying the book item. Through an analysis of the graphical and structural materialities of a book cover's production and its illustrations, we seek to understand the role they play upon the public, while designed readers. From a selection of covers samples belonging to the independent editorial market, we look to understand the cover's visuality as a persuasive element which fundaments that market's action.
\end{abstract}

\section{Keywords}

Illustration. Book cover. Visuality.

\footnotetext{
1 Bacharel em Design e Mestrado em andamento no Programa de Pós-Graduação em Comunicação e Semiótica da PUC/SP. falcão.marialuisa@gmail.com

2 Doutora em Literatura Brasileira PUC/SP. Professor livre-docente pela Faculdade de Arquitetura e Urbanismo da USP. Professora do Programa de Pós-Graduação em Comunicação e Semiótica da PUC/SP. Idferrara@hotmail.com
} 


\section{VOZES $_{\text {\&IÁLORO }}^{\mid}$}

Itajaí, v. 18, n. 02, jul/dez 2019

\section{Introdução}

A definição do que é ilustração faz parte de um grande debate atual por ser um tipo de manifestação artística que utiliza várias técnicas de procedências diferentes, como o desenho, fotografia e a pintura, agrupados ou não. A capa torna-se, então, uma espécie de fronteira incerta e difícil de ser conceituada, porém, facilmente reconhecida quando apresentada. Segundo Zeegen e Crush (2009: 12), são as ilustrações que capturam a imaginação e permanecem com o observador, pois podem se conectar a momentos da história pessoal do indivíduo.

Em geral, livros têm uma relação muito íntima com a ilustração, presente desde os primeiros manuscritos confeccionados na Antiguidade. Apresentando, no início, ilustrações de temática religiosa passa, depois da invenção da prensa de Guthemberg em 1455, por períodos de modernização do objeto, até à multiplicação de gêneros, temas e novas tecnologias digitais e técnicas de impressão referentes à situação atual do mercado de produção editorial.

Levando em consideração o livro e suas estruturas, podemos apresentar a capa como uma das mais importantes delas, fazendo parte de um objeto comunicativo. A princípio tem papel de proteger o miolo, a estrutura interna, o conteúdo e outras sessões do livro, mas além desta questão física, desempenha atribuições como a transmissão da essência e mensagem contidos no impresso, funcionando como um atrativo para que o livro seja manuseado, aberto e comprado. Sendo assim, as capas possuem inúmeras funções dentro do universo do livro, desde aspectos físicos, artísticos, informacionais, até agir como mecanismo de persuasão do possível leitor.

Alan Male, em Illustration: A Theoretical \& Contextual Perspective (2007: 178) coloca que "embora não seja encarado de imediato como uma embalagem, contextualmente, o trabalho de uma capa não é diferente daquele provido por uma 'caixa' física, e a associação de sua identidade visual é feita como em qualquer outro produto". ${ }^{3}$

Um bom design de capa pode ter grande poder de convencimento do usuário, servindo como grande instrumento de marketing, já que constitui uma estrutura essencial e de destaque, funcionando, para o produto, como uma logo.

Assim, a ilustração e o projeto gráfico do livro devem entender seu contexto e atender às diretrizes da mensagem a ser transmitida através de aspectos artísticos, informacionais e comerciais. Zeegen e Crush (2009: 93) colocam que "garantir que o produto seja adequado para o público-alvo, que continue a vender depois da data de publicação e que continue relevante e novo são aspectos que as editoras levam muito a sério”. O conhecimento e a compreensão do conteúdo são essenciais para a criação e

3 "Although not immediately assumed as packaging, contextually the work of the cover is no different to that provided by the physical 'box' and associated visual identity given to any other product." 


\title{
VOZES $_{\text {\&IÁLORO }}^{\mid}$
}

Itajaí, v. 18, n. 02, jul/dez 2019

disposição adequadas dos componentes formadores dessa "embalagem", incluindo uma boa utilização de identidades visuais correspondentes e aproveitamento dos elementos que podem exercer função persuasiva frente ao usuário.

Partindo disto, o rastreamento de públicos baseado em estudos de marketing e até concepções do senso comum trazem maior categorização destes grupos para, através de concepções anteriores sobre gostos, possíveis reações e preferências, facilitar a escolha de materialidades a serem exploradas nas capas de livros.

\begin{abstract}
Os múltiplos estilos de capa refletem o amplo espectro do público leitor. Em uma livraria, a seção de administração e negócios irá exibir capas muito diferentes daquelas apresentadas nas seções de literatura e poesia. Ao se observar o público, a tendência é que se note diferenças significativas de idade, padrão de vestimentas e sexo. [...] Os diferentes gêneros de livros, mesmo em uma época de globalização, não recorrem aos mesmos estilos de capa no mundo inteiro. [...] Se constata que o design e as capas dos livros podem refletir a cultura local ou nacional (HASLAM, 2010, p. 162).
\end{abstract}

Este tipo de divisão pode soar de teor modulador por categorizar o público através de variáveis que observam experiências históricas, culturais e sociais semelhantes, designando visões de senso comum e comportamentos específicos. Porém, é preciso ter em vista que, mesmo havendo essa estrutura de categorias, é esperado que o público possua características individualizantes que, tendo em vista vivências e conhecimentos pessoais e subjetivos, podem diferir das categorias projetadas para o público.

Sabendo deste rastreamento e categorização de grupos de indivíduos, permite-se questionar sobre a existência de públicos projetados, organizados de acordo com características e cultura semelhantes, visando um possível direcionamento do objeto livro, melhor aproveitando as possibilidades disponibilizadas pelas estruturas visual e material do livro e, principalmente, da capa, a vitrine da narrativa ao usuário.

\section{Capas e projeções}

Andrew Haslam, em O Livro e o Designer II (2010) cita alguns modelos de projeto gráfico de capa e como podem despertar o interesse de possíveis leitores. Primeiramente, capas feitas para coleções, possuindo o objetivo duplo de promover um exemplar específico e a existência de outros títulos da coleção, atrairiam a atenção do leitor por meio da composição de todos os exemplares, quantitativamente, em comparação com outros livros. Capas "que se baseiam em um conceito, buscam representar o conteúdo do livro por meio de uma alegoria visual, um trocadilho ou um paradoxo, fazendo uma fusão inteligente ou divertida entre a imagem e o título" (2010: 165). A lógica em produzir capas 


\section{VOZES $_{\text {\&IÁLOGO }}^{\mid}$}

Itajaí, v. 18, n. 02, jul/dez 2019

desta maneira está em estimular o leitor a se sentir sagaz por entender uma "capa inteligente" e, com o ego amaciado, adquirir o livro por impulso, podendo comprar também outros livros com essa premissa.

O modelo de capas chamadas expressionistas tem esta nomenclatura em referência ao movimento artístico situado no final do Século XIX, onde se defendia a expressão dos sentimentos e impulsos, utilizando ferramentas como a adoção de traços e cores fortes.

São empregadas principalmente em romances e contos, objetivando evocar partes e sentimentos da história através de desenhos, ilustrações, fotografias e outros, a fim de instigar o leitor. A intenção é criar um ambiente onde a imagem, associada ao texto, provoque reflexões e interpretações próprias do usuário sobre as possíveis naturezas do livro, criando uma dinâmica de jogo e até desafio em relação ao modo como estas leituras correspondem verdadeiramente ao conteúdo da narrativa. Esta dinâmica manifesta um poder de sedução e curiosidade, que podem levar à compra.

Assim, podemos colocar duas hipóteses sobre a capa de livro ilustrada: Há a necessidade de se projetar um público-alvo, chamados de leitores projetados; e há uma dinâmica de jogo envolvendo o leitor e as questões postas por ele frente a capa e a narrativa, que só podem ser sanadas após a efetivação da compra. A visualidade e a possível tatilidade da capa do livro, convidam-no a jogar e descobrir de que trata o livro, sugerem-lhe adivinhar o jogo proposto pela expressividade ilustrativa da capa.

A noção de público projetado pode ser especificada como própria de um efeito de antecipação, de modo a prever e esperar ações e reações específicas sentidas e performadas por grupos particulares. A princípio, pode parecer uma hipótese muito semelhante à denominação cabível, e até geral, dos públicos específicos que formam a sociedade, mas podemos diferencia-los no momento em que os públicos projetados são agrupamentos personalizados, de acordo com objetos e propósitos comerciais, além de objetivos informacionais. São constituídos por intercessões ou micro-públicos, de vários públicos particulares, moldados, construídos e projetados a partir da busca de determinação dos usuários.

Esta hipótese da projeção de públicos trabalha com várias sub-hipóteses, ou estratégias. Sobre a visão do objeto aqui tratado, capas de livro ilustradas, podemos perceber que o público é projetado conforme as necessidades de cada narrativa e sua mensagem. Traçam este público de acordo com os possíveis interesses temáticos e sobre o gênero da narrativa, estimulando-o sensivelmente através da visualidade de capa, dentro de suas possibilidades sensoriais, como a dimensão primária de cor, o tátil, e o próprio emprego da ilustração, imagem, tipografia e escolhas de layout.

Além disto, pode ser explorada também a necessidade de determinados públicos e usuários particulares se sentirem únicos, pois a utilização de formatos e materiais incomuns fortalecem a individualidade e criam a ilusão de que constituem possíveis exemplares únicos e especiais. 


\section{VOZES $_{\text {\&IÁLORO }}^{\mid}$}

Itajaí, v. 18, n. 02, jul/dez 2019

O que desejam transmitir e que parcela de leitores pretendem, as capas de livros, atingir? Trabalha-se com uma correlação no momento em que o livro é produzido graficamente considerando concepções existentes sobre o seu possível público, no entanto este público também é pré-selecionado visando tipos de reação e consumo esperados dos usuários.

Dentro destas estratégias que partem da projeção de públicos a partir da visualidade da capa, a construção gráfica, a disposição de elementos, tipografia e a própria ilustração corroboram para resultar no impacto que desejam causar no imaginário do leitor. Este tipo de impacto está ligado à maneira como as capas são dispostas e visualizadas, expandindo sua atuação e seu desempenho frente o leitor.

A hipótese de projeção de públicos se relaciona à importância de entender como este recorte influencia a maneira como sentidos e materialidades são explorados, visando o despertar da curiosidade destes indivíduos. Assim, explorando possíveis formas e estratégias de projeção destes leitores, podemos entender como a visualidade da capa ilustrada pode ser constatada no contexto do livro, já que o planejamento gráfico acontece dentro de dinâmicas visando despertar o interesse do leitor.

\section{Públicos e leitores}

Públicos projetados possibilitam a investigação sobre como um direcionamento de apelos pode afetar esses grupos específicos de pessoas e entender como se diferenciam da noção de públicos formadores de uma sociedade.

Em A Opinião e as Massas (2005), Gabriel Tarde coloca sua noção de público, uma união de pessoas formada pela consequência de desejos e necessidades de cada uma delas, constituindo excitações comuns numa questão de inter-reflexão e sintonia de ideias e paixões, mas, permitindo aos seus membros certo grau de diferenças individuais. Porém, para Tarde, esse conceito de público, em um sentido macro, é formado por fatores como opinião, convergência de ideias entre públicos coexistentes dentro de uma sociedade e imitação, a influência simultânea e persuasiva entre os indivíduos, que ante um senso comum, provocam respostas, reações e maneiras de agir semelhantes.

$\mathrm{Na}$ sociedade atual, a aceleração da velocidade de comunicação e troca de informações favorece a formação de novos públicos, grupos que possuem, entre outros, opiniões, vivências, interesses e juízos de valor compartilhados.

Tarde (2005: 20) coloca que: "cada um de nós, ao comprar o que corresponde às nossas necessidades, tem mais ou menos vaga consciência de exprimir e desenvolver desse modo sua união com a classe social que se alimenta, se veste, se satisfaz em ter tudo de uma maneira aproximadamente análoga”. Dessa forma, é possível entender que, na própria divisão e formação da sociedade, há um público no sentido macro e vários públicos de 


\section{VOZES $_{\text {\&IÁLORO }}^{\mid}$}

Itajaí, v. 18, n. 02, jul/dez 2019

menor escala. Nos dois casos, os indivíduos agem e se comportam de forma semelhante, justificando a estratégia mercadológica de projeções baseadas em estereótipos específicos de micro-públicos, ou seja, utiliza-se convenções institucionalizadas e concepções existentes sobre o comportamento de certos grupos, visando o direcionamento do produto. Por meio destas características definidoras de padrão, esses públicos são projetados para um determinado objeto.

Analisando o cenário editorial, observa-se que o trabalho se subdivide entre autores, editoras, uma formação de equipe responsável pela edição do texto, o projeto gráfico e a ilustração, até enfim chegar ao leitor. O trabalho de briefing, anterior à fase de produção gráfica e ilustração, trata de uma reunião de informações sobre o próprio projeto e a definição das diretrizes e a linha de mensagem a seguir, essencial por ser um momento em que se pode entender melhor o projeto. Possibilitando uma investigação de marketing, essa fase permite entender o contexto geral de leitores, especificando, posteriormente, aspectos do objeto como gênero literário e tema, a fim de definir melhor o perfil de possíveis públicos e projetar os tipos de leitores que se deseja atingir com o livro. Este tipo de critério e projeção favorece também a própria mensagem que se deseja transmitir, buscando antecipar algumas possíveis formas de reação do usuário.

É importante buscar uma noção destes públicos a fim de entender outros fatores ocorrentes no seu comportamento, como a influência de aspectos culturais na prédisposição de escolhas, memórias e comportamentos em comum, inerentes àquele universo e senso-comum do público selecionado. As reações do usuário ao ver um objeto podem ser, de certo modo, previstas de acordo com o que se espera do grupo, considerando concepções de cultura, hábitos e normas enraizadas socialmente. A própria cultura acontece como uma espécie de "bagagem" passada através da vida presente e construída no dia-a-dia social em estruturas como a língua, os costumes e outras convenções da sociedade. Considerar questões como vivências pessoais de grupos específicos, memórias e até aspectos subjetivos, é fundamental por ter grande fator influenciador nas impressões que uma capa pode ter sob possíveis leitores.

A partir disto e da hipótese de públicos projetados, poderemos ver como estratégias de persuasão são exploradas, utilizando elementos de interesse de certos públicos e explorando a visualidade na capa de livro, ou seja, aproveitando-se de elementos visuais, texturas e da própria materialidade do objeto.

\section{Visualidade no contexto do livro}

A visualidade é colocada como uma dimensão produtiva da imagem, mas não se limita a isso, estendendo-se além do visual. A imagem representa uma mediação entre o homem e o mundo, a sua realidade. Assim, é importante levar em consideração a 


\section{VOZES $_{\text {\&IÁLOGO }}^{\mid}$}

Itajaí, v. 18, n. 02, jul/dez 2019

influência que exerce na própria percepção do usuário quanto a um objeto, entretanto, também é necessário observar o efeito de outras excitações sensíveis, como a tatilidade.

No processo de percepção e interpretação da imagem pelo leitor, é reafirmada a importância de símbolos presentes no imaginário da população, na formação de culturas e sociedades, já que "Ao circular pela superfície, o olhar tende a voltar sempre para elementos preferenciais.

Tais elementos passam a ser centrais, portadores preferenciais do significado. Deste modo o olhar vai estabelecendo relações significativas” (FLUSSER, 2011:16-17). O conhecimento de significados, indicações e possíveis referências cabíveis a estes símbolos e outros elementos participantes de uma imagem podem, no momento de produção gráfica e ilustração, direcionar diretrizes de como sugestionar melhor a narrativa do livro e sua mensagem, influenciando o trabalho de designers, ilustradores, editores e outros.

Dentro do universo do livro, explorar sua visualidade significa considerar a ilustração, mas também, o próprio formato, texturas, papéis e layout. Colocando em contexto as capas de livros ilustradas, busca-se entender como esta dimensão pode influenciar e atingir públicos, desde variáveis como a materialidade do livro, até questões como a indução do leitor, através de jogos e dinâmicas individuais ou coletivas, uma segunda hipótese complementar à existência e determinação de leitores projetados.

Podemos colocar nesta hipótese complementar, que os jogos fazem parte de possibilidades de projeção do leitor. As estratégias utilizadas para estímulo do leitor por meio da visualidade incentivam uma dinâmica seletiva, ao sugerirem escolhas gráficas e sua possível relação com a narrativa. Pergunta-se sobre um jogo de "visto e não visto", de informações nas entrelinhas e pistas gráficas contidas na capa, através de seus elementos estruturais e da ilustração. De fato, as dúvidas só poderão ser sanadas; e as suposições feitas a partir da capa, só poderão ser confirmadas por meio da compra e leitura do exemplar, de forma a averiguá-las junto ao conteúdo da narrativa. Esta dinâmica é feita de modo projetado, ao ser articulada de modo que leitores específicos e já programados sejam atraídos ao jogo.

Considerando exemplares de livros de poesia publicados por editoras independentes, podemos observar alguns fatores que buscam incentivar o desejo e curiosidade dos leitores. Trata-se de um exemplo com certo nível de recorte, devido ao gênero poético e a própria característica de serem produzidos por editoras fora do grande mercado. Geralmente de menor porte e menor tiragem, são disponibilizados em eventos específicos ou lojas online e implicam, portanto, em delimitação do público. Esta limitação já se apresenta como um fator de planejamento e projeção dos leitores, além de um agente de indução à compra, pela temática associada ao fato de serem artigos mais exclusivos, disponibilizados à venda em locais específicos. O leitor é encorajado a comprar visto que, as condições limitadoras da oferta constituem elementos que o tornam único e especial. Assim, trata-se de um jogo que envolve sedução e autoestima. 


\section{VOZES $_{\text {\&IÁLOGO }}$}

Itajaí, v. 18, n. 02, jul/dez 2019

Figuras 1 e 2 - Capas dos livros $O$ universo parou e eu continuei rodando e Desaparecida.

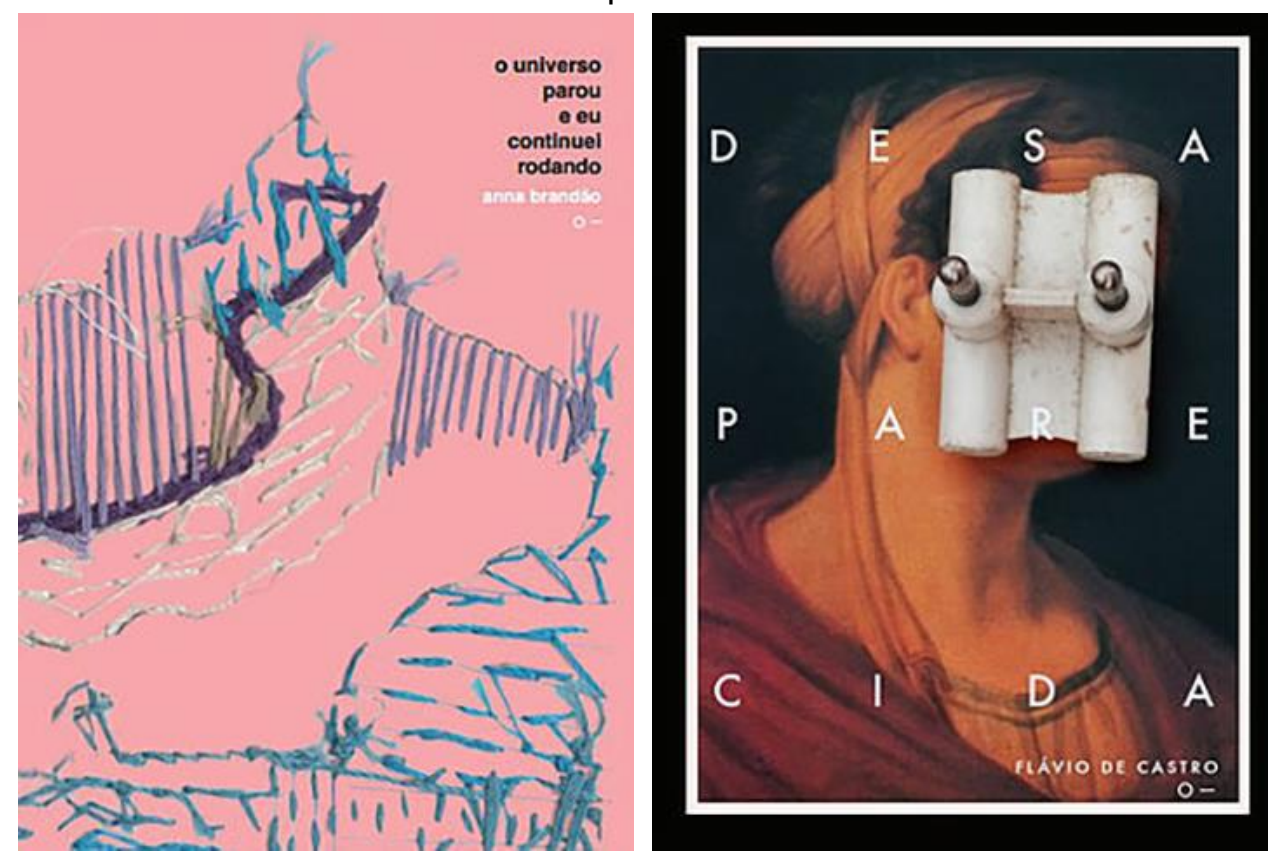

Fonte: < editoraurutau.com.br>; CASTRO, Flávio de. Desaparecida. São Paulo: Urutau, $1^{a}$ edição, 2016.

Em O universo parou e eu continuei rodando (Anna Brandão), a diagramação de título e autor acontece de forma discreta e a paleta revela cores pastéis, já que o maior apelo visual se dá pela construção da ilustração. $\mathrm{O}$ uso de técnicas manuais como a costura e o bordado, editados digitalmente e feitos através da dissimulação de despretensiosidade, permite uma ilusão de textura e de sensação tátil, onde o processo de criação provavelmente incluiu a realização manual da costura, com uma posterior digitalização e pós-produção em softwares de edição digital.

A composição da capa é feita de modo a evidenciar a ilustração da simulação tátil, com um efeito de busca da suposta exclusividade do artigo manual, suficiente para despertar a curiosidade e evocar texturas através das lembranças do leitor. Deste modo, a inclinação ao interesse pela suposta tatilidade e manualidade da capa fortalece o planejamento prévio do leitor, influenciado, também, pela forma como a técnica de bordado buscou formar um desenho com os diferentes estilos, cores e direções de costura produzindo efeito de profundidade e sombra. Além do interesse causado pela simulação de tatilidade, a capa faz com que o leitor especule sobre o motivo do uso de tais técnicas na ilustração e sua relação com o livro e a narrativa, questionamentos fortalecidos pela maneira quase abstrata com a qual o desenho é executado. 


\section{VOZES $_{\text {\&IÁLORO }}^{\mid}$}

Itajaí, v. 18, n. 02, jul/dez 2019

Desaparecida (Flávio de Castro) possui sua capa formada por uma figura clássica feminina, cujo rosto é ocultado pela presença de um objeto que se assemelha a um adaptador de tomada. A imagem é formada por um contraste entre técnicas, ou seja, uma pintura ou desenho convivendo com um objeto do cotidiano, que pode ter sido fotografado e inserido digitalmente, ou ser a fotografia resultante de uma montagem física. Estas possibilidades interferem na dinâmica da capa e despertam a curiosidade do leitor entre ser decorrência da interferência de um objeto físico com uma superfície de imagem, ou uma simulação desta interferência, mas que, em ambos os casos, supõe trabalho de pósedição digital.

É um exemplo de capa que explora sua diagramação e tipografia, em que a existência de uma moldura-margem branca busca o contraste com o fundo preto, direcionando o foco visual ao centro, enquanto a escolha de espaçamento entre letras causa um efeito pois o título da obra ocupa boa parte do espaço disponível, mas de forma a se mesclar à ilustração.

O planejamento do público acontece a partir de escolhas como a importância da diagramação dos elementos, instigando o leitor a questionar a presença dos elementos na capa. Busca fazê-lo "entender" a capa ao supor sobre as relações entre ela, o título e o real conteúdo da narrativa.

Figuras 3 e 4 - Capas dos livros Nojo e Queloide

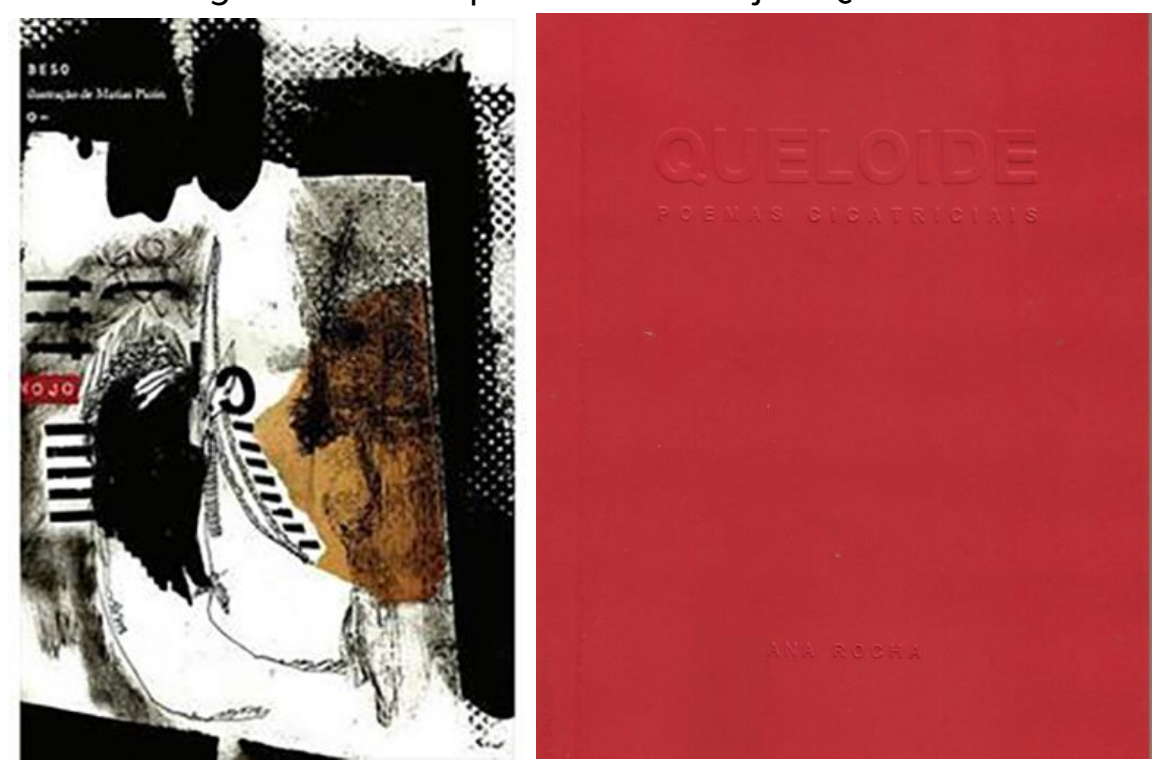

Fonte: BESO. Nojo. São Paulo: Urutau, $1^{a}$ edição, 2016; ROCHA, Ana. Queloide: Poemas cicatriciais. Belo Horizonte: Polvilho Edições, 2016.

Nojo (Beso) trabalha com uma estética mista como o desenho, a pintura feita através de materiais variados e até elementos tipográficos utilizados como formas, colaborando em uma mesma ilustração. As texturas de tinta, utilização de carvão e o 


\section{VOZES $_{\text {\&IÁLORO }}^{\mid}$}

Itajaí, v. 18, n. 02, jul/dez 2019

próprio esquema de cores implica uma aparência "suja", marginal, ou mesmo indicando uma aura em torno de uma figura. A diagramação do texto foi realizada de forma discreta, dando destaque à ilustração, observando-se que o próprio título se encontra na lateral em tamanho pequeno, apesar da cor vermelha ao fundo, utilizada unicamente neste ponto. É facilmente reconhecido pelo leitor que o título se relaciona semanticamente à atmosfera transmitida pela ilustração, em suas texturas e cores.

No caso desta capa, existe grande variedade de elementos e informações, e o próprio exercício de decifrar estes elementos e seu possível encaixe proposto na narrativa, pode funcionar para captar a atenção do leitor, intrigando-o a uma melhor observação. Também é perceptível um trabalho de liberdade pela própria forma variada de utilização de texturas e materiais, possivelmente buscando suscitar, para o leitor, uma apreciação artística.

Queloide - poemas cicatriciais (Ana Rocha), a princípio parece uma capa ligeiramente simples, devido à ausência de uma ilustração propriamente dita, valendo-se da configuração de cor primária. Porém, demonstra conter uma atenção especial à exploração dos sentidos, que partindo da cor vermelha de percepção imediata, favorece a observação do relevo no título e subtítulo, com sugestões táteis. Em uma segunda vista, todos os elementos da capa parecem ser extremamente pensados, desde a linha gráfica visivelmente minimalista, utilizando até a mesma família tipográfica em todo o texto, ausência de desenhos, pinturas e outros tipos de expressão, partindo da sincronia entre título e subtítulo e o objeto queloide.

Assim, o livro apoia-se na curiosidade despertada por uma capa aparentemente básica, que desperta a contemplação favorecendo qualidades primárias, porém dotado de sentido nas entrelinhas, buscando uma possível reação do possível leitor ao descobrir estes sentidos não aparentes, e prevendo o sentimento de sagacidade causado por estas descobertas.

Então, como evidenciado nos exemplos citados de capas de poesia independente, podemos entender melhor como funcionam algumas escolhas gráficas e experimentações com vários aspectos, reconhecendo leitores que se identificam com tais inovações e não excluindo a existência daqueles cuja preferência é capas não-ousadas, que sigam uma linha gráfica padrão já consolidada no design de capas de livros. Desta forma, os elementos gráficos podem ser colocados como estratégias de possíveis estímulos para um desejo e persuasão à compra do objeto livro.

\section{Conclusão}

"Ilustrações influenciam a maneira como nos informamos e somos educados, o que compramos e como somos persuadidos a fazer coisas. Nos dá opiniões e comentários. Nos 


\section{VOZES $_{\text {\&IÁLORO }}^{\mid}$}

Itajaí, v. 18, n. 02, jul/dez 2019

provém de entretenimento e nos conta histórias.” (MALE, 2007: 19, tradução nossa). ${ }^{4}$ Colocada como detentora de poder informacional, a ilustração é parte fundamental de estratégias de convencimento frente ao usuário, implicando sua visualidade e possibilidades temáticas, colaborando para hipóteses da projeção públicos-alvo, além de envolver o leitor em jogos, ao sugerir que descubra a mensagem que o livro e a própria narrativa desejam exprimir, e as conclusões extraídas através do que é representado na capa.

Como visto, algumas estratégias podem influenciar o mecanismo de projeção dos leitores, influenciando-os e determinando-os, no caso de livro, começando por aspectos como gênero e temática. O desenvolvimento de sensibilidade baseado no que é explorado através da visualidade da capa, atravessa materialidades que explorem estes sentidos e, além, faz com que leitores se sintam especiais por meio de experiências supostamente individuais. Estas materialidades possibilitam dinâmicas entre o que é visto na capa e as possibilidades do que podem de fato representar frente à narrativa, fato que só pode ser comprovado através da compra e leitura do objeto.

Penso que nos exemplos analisados, foi possível verificar como, dentro do contexto de livros de poesia independentes, busca-se a construção dos leitores projetados, já bastante definidos por estas circunstâncias. As técnicas compreendidas na ilustração são grande fator influenciador na visualidade e possível despertar do interesse na capa, em alguns exemplos pelo sentido visual, e em outros, auxiliado pela tatilidade e menção à manualidade ou sua simulação. É interessante apontar que, embora o jogo de instigar o leitor a respeito da relação capa - narrativa esteja presente, determinados exemplos apresentam motivadores acentuados a esta curiosidade, em geral, visuais e geram atenção ou estranhamento pela simples presença ou possível razão de ser utilizado.

Embora não percebido nos exemplos vistos, não se pode descartar a possibilidade de capas existirem apenas visando serem objetos de marketing e publicidade, o que não descarta a existência de leitores projetados, mas supõe-se que estes não sejam elementos decisivos na produção gráfica do livro. Assim, implica não-prioridade de uma definição específica do público, atingindo várias dinâmicas citadas como estratégias de projeção de leitores.

\section{Referências}

FLUSSER, Vilém. Filosofia da caixa preta: Ensaios para uma futura filosofia da fotografia. São Paulo: Annablume, 2011.

4 "Illustration influences the way we are informed and educated, what we buy and how we are persuaded to do things. It gives us opinion and comment. It provides us with entertainment and tells us stories." 


\section{VOZES $_{\text {\&IÁLORO }}^{\mid}$}

Itajaí, v. 18, n. 02, jul/dez 2019

HASLAM, Andrew. O Designer e o Livro II. 2 $2^{\underline{a}}$ Ed. São Paulo: Rosari, 2010.

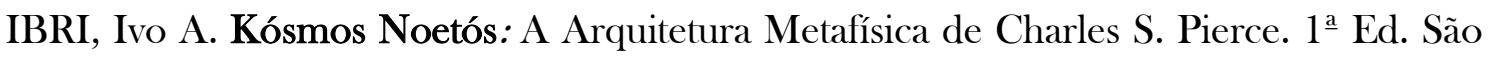
Paulo: Paulus, 2015.

LUPTON, Ellen. Indie Publishing. $1^{\text {a }}$ Ed. São Francisco: Chronicle Books, 2008.

MALE, Alan. Illustration: A Theoretical \& Contextual Perspective. Lausanne: AVA, 2007.

TARDE, Gabriel. A Opinião e as Massas. São Paulo: Martins Fontes, 2005.

VELHO, A.P.M. A Semiótica da Cultura: Apontamentos para uma metodologia de análise da comunicação. In: Revista de Estudos da Comunicação. Curitiba, n. 23, p. 249-257, set/dez. 2009.

ZEEGEN, Lawrence; CRUSH. Fundamentos de Ilustração. 1 $1^{\text {a }}$ Ed. Porto Alegre: Bookman, 2009. 